\title{
Thought and language
}

\author{
D. Laplane \\ Clinique des Maladies du Système Nerveux, Hôpital de la Salpêtrière, 75651 Paris, Cedex \\ 13, France
}

Correspondence: D. Laplane at above address

\begin{abstract}
From aphasics' self records, common experience, changes in signification of sentences according to a verbal or non-verbal context, animals and non speaking children performances, it seems possible to get some evidence that thought is distinct from language even though there is a permanent interaction between both in normal adult human beings. Some considerations on formalisation of language suggests that the more formalised it is, the less information it contains. If it is true, it is not reasonable to hope that a formalised language like that used by computers may be a model for thought. Finally, the lack of status of thought, as far as it is a subjective experience and the impossibility of giving it a definition as far as it exceeds language, make it clear that in spite of progress in scientific psychology, thought, per se, is not an object for science.
\end{abstract}

\section{INTRODUCTION}

Wittgenstein's basic assertion: "the limits of my language mean the limits of my world" still influences the development of research in science and in philosophy. Cognitivists strive to reduce thought not only to a common language but to a formalised computerised language. Philosophers have believed for some time that the study of language would block the mechanisms which create philosophical problems and the confusion they represent. The school of logical positivism stemmed from this assertion and so did "critical philosophy" which considers its role merely as one of questioning questions.

The aim of this paper will be to challenge this basic assertion and to show that thought does exist without language, that formalisation of language narrows its field of application and that the more formalised it is, the narrower is its meaning or significance. If it is true, there is no hope that a formalised system such as a computer could account for common language or even that any language could account for thought. This issue is of considerable importance if applied to sciences like artificial intelligence or cognitivism but clearly it applies also to science in general even though its methods may approach and circumscribe them. Furthermore, it will appear that thought in itself cannot be defined and that it is judged only by personal experience: it is essentially an inner and subjective experience. For all these reasons, thought as such is not an object for science. Research in psychology and neuropsychology cognitivism and so on can only circumscribe its realm but not resolve its enigma. It is of importance, too, for philosophy and ethics because a discussion on grammar will never resolve any philosophical problem.

\section{CASE REPORT}

We shall start with an everyday medical observation. The following case is intended to show that abstract reasoning may be developed quite extensively without the help of words. It concerns a 58-year-old woman who had suffered from common migraine since childhood. One day, while shopping in a supermarket, she realised she could not read her own shopping list, or more accurately, as she put it, she could hear the words: sugar, salt, oil, in her head, but they did not mean anything. She realised that something was going wrong inside her head. As a doctor's wife and migraine sufferer, she knew something about neurological disorders, and she thought a migraine was starting and that she should take some aspirin. We must point out that, the lady had not, at this point, diagnosed aphasia-which would have been beyond her competence-but a migraine, although the headache had not yet started, and she had not experienced such troubles before. After a few minutes, she thought she would go to the cafeteria and stopped at the information desk to ask the way. But once there, she could not say more than "Can I, can I ..." The hostess was attentive and helpful. The patient thinks she heard: "Take your time, madam, take your time." Eventually, the patient managed to say something like "drink" while thinking that perhaps it would be thought she had had enough already. The hostess showed her the way, although whether it was the word or the gesture which were understood is not clear. Anyway, on arriving at the cafeteria, the patient was at last able to ask for an orange juice and the disorder disappeared. It had lasted about 15 min. It was soon followed by teichopsia and narrowing of the field of vision which made it necessary to read the 
prices in segments. The neurological symptoms resolved after about half an hour. A dull headache now started. When the patient was examined, half-an-hour later, investigations were normal. Only the headache remained.

\section{DISCUSSION}

The difficulty with this case is the lack of examination during the crisis. Why choose it when there is well documented literature (Lecours and Lhermitte, 1979; Newcombe, 1987) clearly showing that aphasics are capable of dealing with concrete situations, even very complex ones, at any rate considered as non-verbal situations? Because of the patient's mental process in diagnosing and seeking a remedy: not only is this an abstract process of relatively high intellectual level (in the doctors' opinion), but it is seemingly impossible to formulate or to think about without words in the absence of any previous experience. Did this mental process really happen without the help of words? The interest of this example depends on the fact that the patient's disorder was probably not merely pure alexia for she was quite clear that she could "hear" the words she read but that they did not mean anything to her. It would seem, then, that the patient had lost her inner language, although she cannot be precise on the subject, which is interesting in itself (absence of clear cut delineation between thinking with and without words). In any case, she could not utter a word when she tried to. It is inconceivable that, when ordinary words like sugar or oil failed her, the patient could find words like migraine or aspirin for her reasoning. The fact that she understood such easy to guess sentences as "take your time, madam" is not sufficient to make us doubt this. It is important to remember that the patient did not yet have a headache, that she never had such troubles before, and that her aphasia could not in any way have for her any connection with previous migraines. For what could be the inner representation for migraine or aspirin when she could not possibly have any symbolic representation of them, in the linguistic sense of the word, or any analogous image, since the sensations felt were totally new? Abstraction is difficult to define. In this case it could well correspond to what a migraine actually is: neither word nor sensation, neither symbolic nor analogous representation, perhaps a constellation of meanings or connotations learnt through experience or teaching which all converge toward the concept when some of them are simultaneously activated. The concept would be the point of convergence of all these different elements. The concept of migraine appears then as essentially subjective, peculiar to each speaker according to his own experience. Indeed, this is what is shown in practice: each patient has his own concept. An interpretation of the concept very far from a formalisation has the disadvantage of not being heuristic: how do you use a notion as vague as the convergence of elements which probably are themselves convergences of elements? Indeed, this interpretation does not mean to be a scientific explanation but a philosophical remark. It may not please for this very reason, but sometimes, reality is not as pleasant as we would like it to be. Anyway, there are advantages in this interpretation. It is strikingly similar to what happens in particulate physics where each particle is nothing but the result of interference patterns of elements themselves only interferences of interferences. It also opens the door for motivation and affectivity in the process of understanding. Before her attack of migraine with neurological symptoms, our patient had clearly been motivated to learn, through reading and talking, some details about migraine. In the same way, at the time of her attack, it was very comforting for her to choose a reassuring interpretation. In spite of the discussions around the notions of meaning which are rather difficult when we remain within the limits of formal language, or rather because of the failure of those very discussions, it is difficult to avoid going back to a definition which stems from common sense: what is meaningful to us is what corresponds to our current interest. It may be consistency if we are concerned with logic. Even in this case, we have a feeling of satisfaction when we find it, and an uncomfortable feeling when we have difficulty in finding it. When the problem is one of health, possibly serious, like a mental disorder (in this case aphasia), it is even more difficult to neglect affective data. Our patient's "logical" reasoning referred to all that: without a doubt, to a "thought".

The idea that a wordless concept really exists in our mind as the centre of a network of meanings refers to our ordinary experience or to what could be called here the psychopathology of daily life: it happens quite often that we fail to recall, either temporarily or for a longer period of time, the name of an author we know; he still exists for us. Most of the time, to represent him in our mind, we have neither an analogous image (portrait, physiognomy) not a symbolic image (words), but only the convergence of his writings, and even then, if we are not too familiar with them, we are not able to name them; all we have kept from them is a theme or even an atmosphere! Sometimes the name comes back, sometimes we must refresh our memory. But, if we see his name on a list, we know whose it is without hesitation. This fragmentary but common "amnesic aphasia" could, it seems to me, give us a reduced image of what patients suffering from certain types of aphasia might feel.

One could possibly object that we are confronted with another case of dissociation between covert and overt functioning. We know, for instance, that the brain can use data to which our consciousness cannot have access. For example, a target in the field lost in an hemianopsia due to a cortical injury may be pointed out in space or caught with 
some precision (Perenin and Jeannerod, 1975). Even an intact brain uses elements which are not consciously registered in most cases. If someone is asked to tell the time from an unfamiliar watch, he cannot usually say whether the face had arabic or roman numerals or no numerals at all. Yet these are marks necessary for orientation, and therefore for reading (Fodor, 1983). One could conceive, by stretching facts a little, that words which don't come to our consciousness play their part all the same. This objection, acceptable at a pinch, seems shaken when you consider what Bisiach (1988) calls language without thought. He takes as an example a man suffering from left hemiplegia and hemianopsia with severe anosognosia. The examiner having taken the patient's left hand in both his hands asks him what are those hands: "Your hands, answers the patient."-_How many?"-_"Three"_-"Have you ever seen a person with three hands?"-_"Hands are at the ends of arms. If you have three hands you must have three arms." In the discussion of the case, Bisiach comes to the conclusion that in such an instance the patient's language area is neither deteriorated nor disconnected but ill informed. If this conclusion is accepted, it must also be accepted that thought does not reside in words but wherever the three hands were perceived as it were.

Another type of dissociation between thought and language exists in the puns where we give several meanings to the same expression. It is also rather remarkable that the meaning of a sentence or even of a whole text may be completely altered through mere change of context. This use of context is seen most commonly in the erotic register: if someone says "my pussy has caught a cock", you'll see the scene easily; if someone says "my cock has caught a pussy", you'll be rather surprised by this piece of news. Now, when you realise that the first sentence was said languidly by a woman, and that it was her partner who answered: "not at all, it's my cock which has caught the pussy", the whole thing becomes clear without one word being changed. According to the circumstances, the context may be given by verbal annotations or by a concrete situation. You might retort that in erotic slang the word pussy has a precise genital meaning. The same cannot be said of the word cock: its meaning must be looked for in a different vocabulary, that of children where the penis is called a cock. Although this use is not universal, everybody will understand, except perhaps, foreigners who might wonder if there is not yet another meaning. The break with explicit vocabulary may be yet greater: after a long drive on a torrid afternoon, a $31 / 2$-year-old child and his grandparents stop for a drink at a village fountain. A little later, the car passes, with some difficulty, a rather unsteady motorcyclist. "That one was thirsty as well", says the grand-mother. "You must not drink too much wine", adds the child thus showing that he perfectly understood that concrete situation, the context and his grand- mother's allusion. This story is interesting in two ways: first of all because having been thirsty taken literally does not mean having drunk and even less having drunk too much wine; secondly because a $31 / 2$-year-old child who is a long way from mastering the language is more sensitive to the general context than to the words, which nonetheless support the meaning.

We can take another direction to explore the necessary distinction between thought and language: we can wonder about thought as it appears in animals which are obviously intelligent but do not talk. Here we must distinguish between animals which will never talk and children before the age when they can talk or whose language acquisition is slowed down by an infirmity.

Regarding animals, we usually think of monkeys, of primates, notably of Sultan, the chimpanzee made famous by Kolher (1951). This animal, which had been kept hungry, was placed in a room where a banana was hanging from the ceiling. To get at it, he showed great ingenuity: first he climbed on to a box left in the room which he dragged underneath the banana; when this was not enough, he piled boxes up, but still couldn't reach. Finally, he slid into each other two special sticks, left in the room for that purpose, climbed on the piled up boxes and knocked down the fruit. The chimp showed the ability to make mental representations, work out relationships, and set a strategy, all activities to which it is difficult to deny the status of thought. Without language, Sultan reached a rather advanced level of concrete reasoning. Progress has been made in primatology, and it has been possible to inculcate into chimps some elements of language (Premack, 1988). The introduction in the teaching process of the words "same" and "different" greatly improves the animal's performance in tests using the recognition of similarities and differences not only between two objects but between the relationships of objects considered two by two. This concerns the instrumental use of similarity or difference, and not the recognition of one or the other which chimps possess naturally, without training, as can be shown by other tests. However, it must be pointed out that language use is not essential for the success of tests using this similarity, but that learning takes infinitely longer without it and that success is not transferable from one task to another inside one series contrary to when language is used during training.

The normal 3-4-year-old child does not succeed any better than the chimp in using conceptual coupling, but the problem can be greatly and instantly simplified for him by showing him that two similar objects make a case for similarity and two different ones a case of difference. The child spontaneously uses physical similarities but not similarities between relations but can learn to do so; the chimp does not use either spontaneously but can learn to do so. The obvious superiority of the child over the chimp even 
before the child acquires language shows that this ability is not due to the advent of speech.

There is a great variety of research to confirm this. A classic work is that of Piaget's (1959) which showed the progressive build-up of sensori-motor patterns in the child before any language acquisition. These patterns derive from a motor experience and take on a value generally applicable to a group of actions. They do not develop in parallel with language. The child does not pass the so called test of conservation of liquids at an age when he first has the verbal ability to express it. Up to the age of seven or eight the child thinks that a constant volume of liquid in a glass increases or decreases if the width or the height of the glass changes: he judges solely from the height of the column. Later, he estimates that the quantity of liquid is unchanged not because his vocabulary has widened but because his logical abilities have grown through cerebral maturation. These experiments have been criticized. The results could be different if the tests are presented in a nonverbal way. This criticism does not alter the conclusion about the distinction between verbal and non-verbal thought.

The role of cerebral maturation is shown in a particularly striking way when comparing Piaget's $A B$ test and the delayed response in the monkey with a prefrontal lesion (Diammond, 1988). Before the age of $7 \frac{1}{2}$ months an infant cannot find a toy which he has seen hidden in a hole a few seconds earlier. Between 7 and 11 months he can find the toy in hole $A$ but if the hiding place is changed to hole $\mathrm{B}$, he will inevitably return to $\mathrm{A}$, if one imposes a long enough delay before letting him search. The length of time elapsing between hiding and beginning a successful search increases with age. The delayed response test given to the monkey is essentially the same. It is easy to train a monkey to retrieve a candy from one of two hiding places where it has been hidden $10 \mathrm{sec}$ earlier. The monkey with bilateral prefrontal lesion loses this ability and goes back to the stage of the infant between 7 and 11 months. Generally speaking, children behave in many instances like some adults with frontal lesions: grasping in the very young, using objects and imitating behaviour, lack of inhibition as in earlier behaviour (often challenging a forbidden behaviour such as: "don't touch that key" for instance) or a combination of the two as in the game "Simon says". The difficulty persists beyond the acquisition of language, otherwise there would be no such game. In brief, it is clear that children organise their experience and their activity differently from adults, but the difference does not appear to be due to adults possessing language and children not possessing it. Rather, it must be admitted that it lies in cerebral maturation, particularly that of the frontal area.

I hope I have sufficiently shown that Wittgenstein is removed from reality. It has been said that Berkeley could not have kept his immaterialist idealism if, as a bishop, he had not been relieved of all material needs. It could be said, I think, that if Wittgenstein had been a neurologist, he would never have equated thought to language.

The preceding argument may have seemed rather long, just to end in a conclusion with which the neuroscientific community on the whole readily agrees. But it will be the basis for another argument which will be much more difficult for them, especially cognitivists, to accept. Indeed I am about to attack the cognitivists' central dogma which reduces thought as a whole to a computer language; a formal language including our "intentionality". For this, we must go back to the migraine case studied earlier. It was seen that, in current language, the word migraine did not correspond to a precise definition but to a convergence of experiences, of information and of essentially subjective affects. This is hardly less true of medical language, when clear physiopathological definition is absent. A definition such as that offered by the ad hoc committee is an attempt at a first degree of formalisation of language so that the word "migraine" corresponds only to a specific situation, as well defined as possible. It will be noted, however, that in the process, the concept of migraine loses part of its field, including its legitimate one, defined as all the manifestations most probably stemming from the yet unknown migraine physiopathological processes. It is unlikely that there is a clear cut distinction between cephalalgias which embrace two criteria and those which include three and some patients may, in time, pass from one group to the other. Obviously, this last remark is not a criticism of classifications matching strict definitions. They are indispensable for certain types of epidemiological or therapeutic studies. On the other hand, sticking closely to them in approaching a particular patient could possibly deprive him of active treatment. Which is to say that formalisation, even a rough one, is not necessarily an advantage; a lot depends on your objective. Even though medical progress is linked to an increase in precision of the language, the advantage is not universal. There could actually be regression if the method were to be extended beyond the sciences, beyond objective knowledge of the universe. This is true even though formalisation is incomplete as it is generally in science. Perfect formalisation exists only when the semantic relation is independent of all context, that is to say, in the end, when the symbol does not mean anything more than itself. This language may allow exact calculations but ambiguity returns as soon as it is applied to real situations. Besides, it seems difficult to consider any formal language as more than a part of language in general. Evidence for this could be that formal language can be discussed in current language but the reverse is never totally possible, in other words, current language is a metalanguage for any formal language. If this is true, how could a part express what the whole cannot include?

Eliminative materialism pretends it can solve all these 
problems by linking up any psychology, any thought to a "folk psychology" itself of little interest. Only cerebral functioning and its objectivity should be taken into consideration. Within neuro-sciences, this view is surely excellent, and I don't think we should have any illusion about the value of empirical subdivisions in psychology. Gall's amusing attempts to localise the love of ownership, the love of offspring or friendship serve as a warning. Our distinctions may be arbitrary, but the existence of thought is not. All statements on anything, including the functioning of our brain, exist only within thought. An obvious difficulty is that eliminative materialism cannot be explained through cerebral functioning. If the thought of the advocates of this theory is true it is itself part of the folk psychology (it is not cerebral functioning itself) and it will merely bear witness to the existence of a particular "folk" psychologically conditioned to think in this way.

The root of the problem lies in the lack of status of thought in the philosophies mentioned earlier, and in the mind of most neuroscientists. This lack of status and, of course, of definition allows any kind of statement including the most reductionist. To try to clarify this, I shall refer to a last example of thought without language, perhaps the most striking, that of the right hemisphere in split brain cases.

With reservations it can be stated that only the left hemisphere is the seat of language, but that in the non-verbal field, when the manipulation of spatial images is required, the performance of the right hemisphere is superior. Copying a drawing, understanding mime, the interrelation of shapes, discriminating visual and tactile shapes, transforming and transposing shapes, estimating the size of a circle from a small segment of arc, categorising groups of various shapes or sizes, recognising a whole from its parts, intuitive understanding of geometrical properties, in all these operations the right hemisphere is superior. Sperry concludes "Clearly, the right hemisphere perceives, thinks, learns, remembers, at a totally human level. Without the help of language, it reasons, takes "cognitive" decisions and works out new, voluntary actions. It even generates typically human emotional responses when confronted with affect-laden situations" (Sperry, 1984). Sperry finds very significant the emotional behaviour of right hemisphere patients who were shown affect-laden photographs: popular and unpopular public figures, family photos, risqué scenes, for example. The results are quite comparable to those when the left hemisphere is questioned or in free vision, and seem related to the patient's original personality. When asked about the future, the right hemisphere answers with the same concerns, the same evaluation of time. All this occurs without language support. True, the experiences are not as pure as one would wish. The performance of the right hemisphere in relation to words spoken one after the other is only just inferior to that of the left hemisphere, but language is much more than isolated words. Moreover, it is well established that either hemisphere may use, up to a point, the data stored in the other, while not being conscious of them (Sergent, 1987). This brings us back to the interferences mentioned before of unconscious data in the shaping of judgement. Here again, they don't seem sufficient to counteract the evidence that the right hemisphere carries out complex operations without the help of language.

Does this mean that it thinks? We pointed out from the start the weakness of any statement on the subject as long as thought or thinking was undefined. Most of those who use this concept carefully avoid defining it. We admit, together with Lhermitte and Lecours (1979), that such definition is difficult to give, and the results of their efforts confirm their doubts: "Thought is the entirety of psychic activities." Now, we only have to define "psychic activities"... Instead of a definition we must be content with an enumeration: being attentive, calling back memories, imagining, comparing, judging, reflecting. In fact, all these terms should be defined, which immediately highlights the limitations of language: any definition starts a vicious circle for the terms then have to be defined one after the other. Should we then sanction those who do not even try to define thought? Yes and no. Yes, if they want to tell us about it, no if they don't try to. On this point, Wittgenstein was right to say: "What we cannot talk about, we must pass over in silence". It is a way to leave room for the unspeakable. Unfortunately, for Wittgenstein, the unspeakable is also unthinkable, and this assimilation of thought to language is difficult to justify even in its negative form as we have tried to show. But why such difficulties in defining thought? Simply because there is nothing anterior to it, logically or chronologically. Whatever we may say (or think) about it, stays within itself. Therefore there is not the slightest hope that any language, be it scientific or philosophical, rational or poetic, might define thought in its entirety. The best that speech may do is to show it in its inaccessibility. This does not exclude the possibility of science approaching some of the mechanisms which govern if not the formation of thought as such, at least the formation of some of the elements which make up thought. The real progress in neuropsychology points the way, but these partial successes are but snares to persuade the unwary that one day thought will be defined. The point is not to question the legitimacy of cognitive research. There is no doubt that some phenomena, including language can now lead, up to a point, to a computional interpretation. Cognitivists claim as their domain any processing of information. We must let them be, and wait to see how far they will go, without limiting the scope of their investigations. But it may be foreseen that the results will never be more than partial. In any case, many admit that some aspects of thought might be foreign to this type of 
approach. Phylyshin (1989), for example, writes: "It would not be entirely surprising if some of our favorite cognitive phenomena had to be abandoned." And he cites moods, emotions as well as consciousness. Similarly, Fodor admits that only input systems are modular, not those called "central". Let's encourage them in their scepticism because language lies within thought, is not coextensive with it, and therefore could not exhaust it. If this is true of current language in particular, it should also be true of formalised computer language.

Moreover, formal systems of logic have their own limits since Gödel's theorem, stating that some true propositions cannot be verified within their own frames, applies to them in particular. It would be useless, therefore, to expect from them a complete explanation even if some instrumental aspects can be clarified by them.

\section{CONCLUSION}

In the end, it seems unreasonable to insist on defining thought. It must be emphasized that an object which is not possible to define is not an object for science. If we wish to talk about it, we must at least try to designate it in some way or other. I shall only outline some answers which I have developed in another work (Laplane, 1988). What characterises thought rather than what defines it, is that we only know it through personal and immediate experience. It is the eminently subjective phenomenom. All we know of others is their behaviour, including verbal behaviour, and we attribute to them a thought only to the extent that their behaviour corresponds to the feelings we have already experienced, in a word because we see in them a similarity to us. We act in more or less the same way with our pets when their behaviour makes us think, perhaps wrongly, that they have the same feelings as us. As we go down the animal scale, this attribution becomes more and more difficult, then quite impossible when the simplicity of the nervous system becomes such that, proportionally, we know more about it. Science, because it is objective, will not tell us anything about animals' thought. It is obviously not just coincidence that among the list of "psychic activities" given before we don't find "tasting, loving, suffering ...", in a word, what concerns us and, in the end, gives meaning to all cognitive activities. This is because science, in its deliberate objectivity runs into its own limitations. We know the success of this objectivity, but we must acknowledge its limitations. This does not imply in any way that the scientific scope should be arbitrarily restricted: exploring the field of psychology through objective means might, at first glance have seemed a meaningless enterprise; we know how fruitful it has been, and there are good reasons to believe that it will go on progressing. However, even if the neurosciences must try to extend their limits, we must not deceive ourselves about the existence of these limits.
In the end, what answer can be given to the question: does the isolated right hemisphere think? Apart from the fact that the concept of hemispheric function may be a mythical idea, we must not even ask the question. The isolated right hemisphere is too different from us for any answer to have any meaning. What is certain is that complex cognitive operations are possible without the help of language. Even if we keep to a vision of thought drastically reducing it to its cognitive activity, the answer to the problem of the relationship between thought and language is that language is an essential instrument of human thought, but that thought exists beyond language. The same could be shown of any cognitive activity: memory, praxias, gnosias, attention, etc. If we examine the cases of aphasics and of all those whose cognitive functions are altered, this answer is not merely academic but most of all humanist which is to say ethical. It means that we cannot assess the persisting thought of demented people and for that reason that they remain similar to us.

\section{Acknowledgement}

I am indebted to Dr R. Gibbins and Mrs Magali Gibbins Laplane for translation of this paper into English.

\section{REFERENCES}

Bisiach, E. (1988). Language without thought. In Thought Without Language (Ed. L. Weiskrantz), pp. 465-484. Oxford Science Publications, Oxford.

Diammond, A. (1988). Differences between adult and infant cognition: is the crucial variable presence or absence of language? In Thought Without Language (Ed. L. Weiskrantz), pp. 337-370. Oxford Science Publications, Oxford.

Fodor, J.A. (1983). The modularity of mind. An essay on faculty psychology. Massachusetts Institute of Technology, Cambridge, MA.

Kohler, W. (1951). Mentalities of Apes. Humanities Press, New York.

Laplane, D. (1988). La Mouche dans le Bocal. Plon, Paris.

Lecours, A.R. and Lhermitte, F. (1979). L'Aphasie, pp.622-624. Flammarion, Médicine et Sciences, Paris.

Newcombe, F. (1987). Psychometric and behavioural evidence: scope, limitations and ecological validity. In Neurobehavioural Recovery from Head Injury (Eds H.S. Levin, J. Grosman and H.M. Eysenberg). Oxford University Press, Oxford.

Perenin, M.T. and Jeannerod, M. (1975). Residual vision in cortically blind hemifields. Neuropsychologia, 113, 1-17.

Phylyshin, Z.W. (1989). Computing in cognitive science. In Foundation of Cognitive Science (Ed. H.I. Posner), p.86. MIT Press, Cambridge, MA.

Piaget, J. (1959). Le Langage et la Pensée Chez l'Enfant. Delachaux et Nestlé, Paris.

Premack, D. (1988). Minds with and without language. In Thought Without Language (Ed. L. Weiskrantz), pp. 46-65. Oxford Science Publications, Oxford.

Sergent, J.A. (1987). New look at the human split brain. Brain, 110, 1375-1392.

Sperry, R.W. (1984). Consciousness, personal identity and the divided brain. Neuropsychologia, 22, 661-673.

Wittgenstein, L. (1963). Tractatus Logico-Philosophicus. Routledge and Keegan Paul, London. 


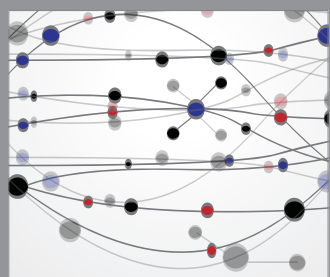

The Scientific World Journal
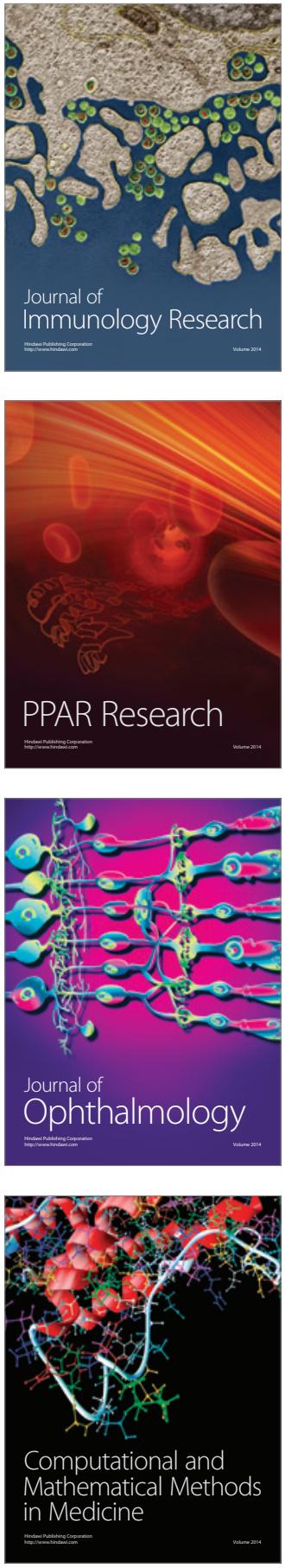

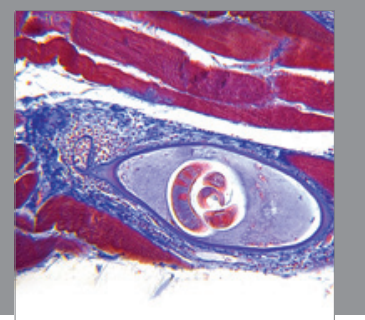

Gastroenterology

Research and Practice
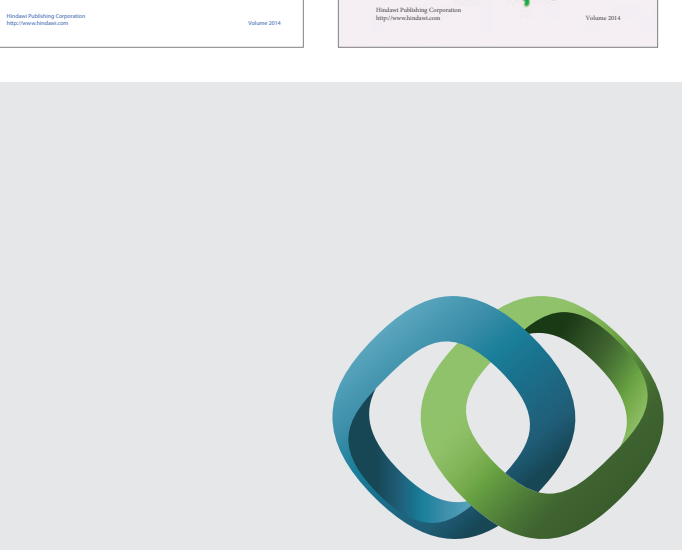

\section{Hindawi}

Submit your manuscripts at

http://www.hindawi.com
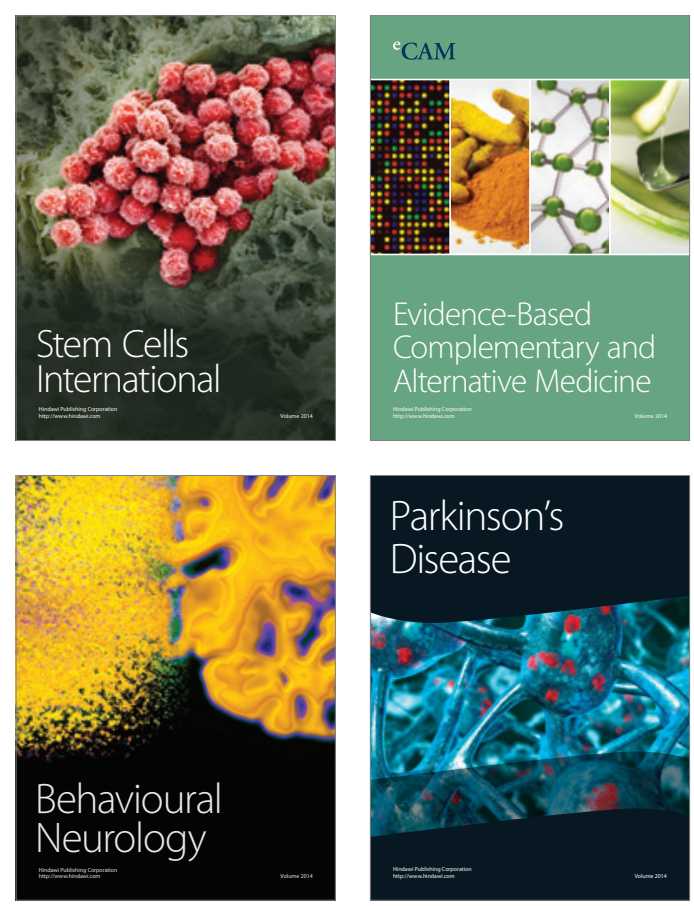

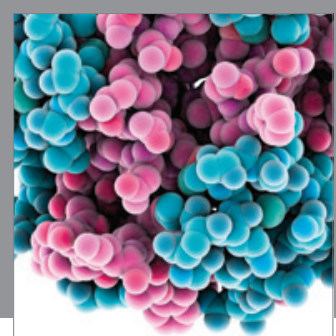

Journal of
Diabetes Research

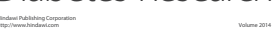

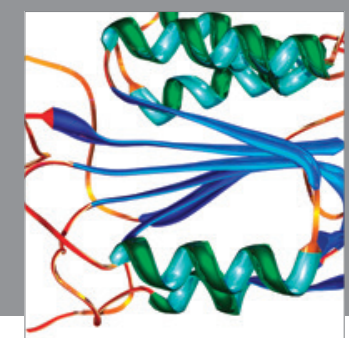

Disease Markers
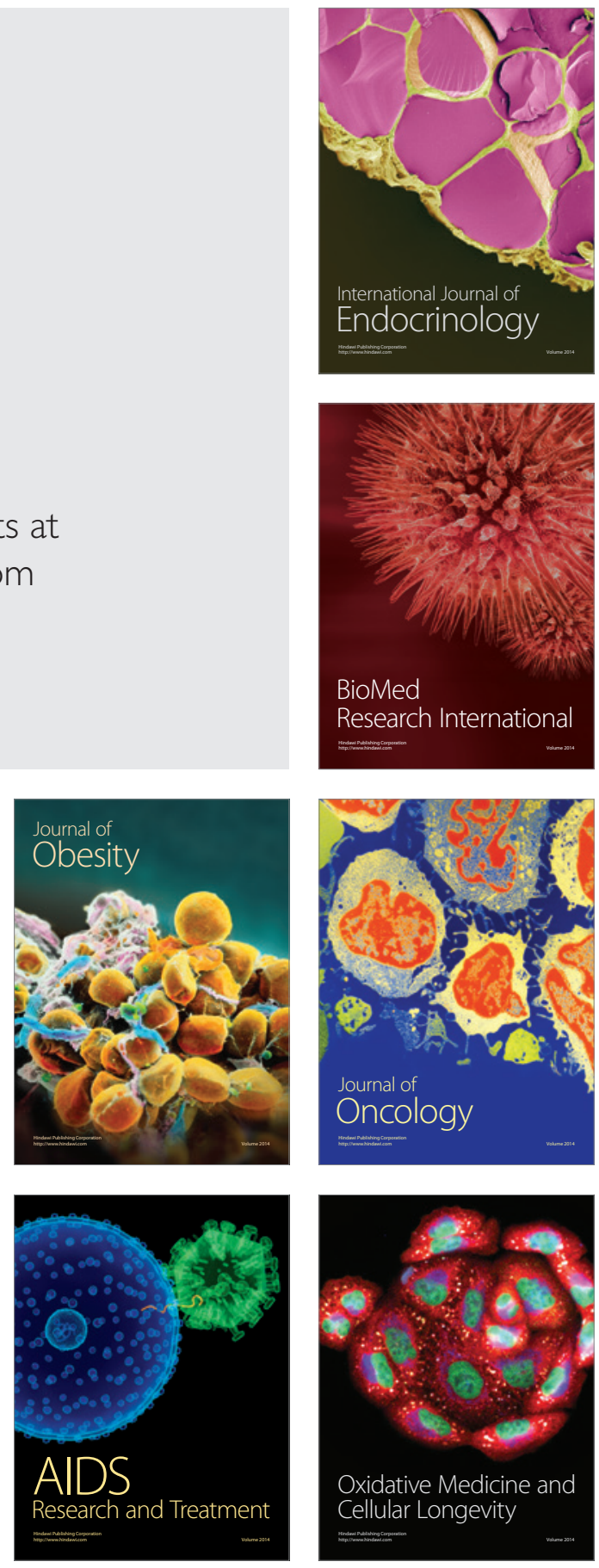